\title{
The Effectiveness of Surgical Methods of Treatment of Pulmonary Tuberculosis for Patients with Multidrug Resistant at Adequate Chemotherapy (Retrospective, Case Control, Comparative Research)
}

\author{
Kulakhmet Dildakhmetovich Yerimbetov, Askar Shintasovich Zetov, Tleukhan Abildayev, \\ Gulbadan Sabitovna Bekembayeva, Shahimurat Shaimovych Ismailov \\ National Center for Tuberculosis Problems, Ministry of Health, Almaty, Republic of Kazakhstan \\ Email: k.d.erimbetov@mail.ru, askarzetov@mail.ru, t.abildaev@ncpt.kz, gbekembayeva@gmail.com, \\ ismailovshah@mail.ru
}

Received 13 March 2014; revised 7 April 2014; accepted 14 April 2014

Copyright (C) 2014 by authors and Scientific Research Publishing Inc.

This work is licensed under the Creative Commons Attribution International License (CC BY).

http://creativecommons.org/licenses/by/4.0/

(c) (i) Open Access

\begin{abstract}
In this article, there are given results of comparative studying of efficiency of surgical and conservative treatment of 277 patients with multidrug resistant tuberculosis. The effectiveness of the surgical treatment of the main group of patients against the background of chemotherapy with anti-TB chemotherapy with the drugs of the reserve line has been compared with two control groups: Group I-Surgical intervention was implemented with drugs of the first line, Group II-Chemotherapy was conducted with anti-TB drugs of the second line without surgical intervention. Treatment outcomes in three groups were stated after cohort investigation, and following results were obtained: Effectiveness of surgical treatment of patients of the main group with MDR TB treated with anti-TB drugs of the second line constituted $98.0 \%$ versus $53.7 \%$ in the Group II. Effectiveness of conservative treatment of patients in III (control) Group constituted $\mathbf{7 4 . 4 \%}$. Analysis of results obtained showed that the outcomes in the main group after regimen completed were higher by 1.8 times than in patients operated against the background of treatment with the drugs of the first line and by 1.3 times higher than effectiveness in patients in the Group III $(P<0.01)$. Effectiveness of the treatment in the Group II was obtained through implementation of collapsesurgical interventions. In this article, the statistical program STAT 10 was applied.
\end{abstract}

\section{Keywords}

Surgical Treatment, Drug Resistance, Chemotherapy

How to cite this paper: Yerimbetov, K.D., Zetov, A.S., Abildayev, T., Bekembayeva, G.S. and Ismailov, S.S. (2014) The Effectiveness of Surgical Methods of Treatment of Pulmonary Tuberculosis for Patients with Multidrug Resistant at Adequate Chemotherapy (Retrospective, Case Control, Comparative Research). Surgical Science, 5, 164-169.

http://dx.doi.org/10.4236/ss.2014.54029 


\section{Introduction}

Through the continuous taking of the modern antibacterial drugs, their use without any system, disturbance of regimens administrated, drug resistant forms of pulmonary tuberculosis can be developed, which are frequently difficult for treatment and lead to the great epidemiological danger. The high level of drug resistance of $M$. tuberculosis to antibacterial drugs of half of patients with newly detected tuberculosis is the reason of non-effectiveness of the chemotherapy [1]-[5].

Only in $50 \%-75 \%$ of cases, the implementation of the standard regimens of chemotherapy with anti-TB drugs of first line at poly-and-multi-resistant forms of tuberculosis allows to stop bacteria excretion. Implementation of anti-TB drugs of the second line among newly detected patients with drug resistance allows to obtain the effectiveness (stopping bacteria excretion) in $93.8 \%$ of cases, and in the group of chronic patients in $75.5 \%$ of cases [6]-[9].

Meanwhile, in $15 \%$ - $20 \%$ of cases of patients with drug resistance, stopping of bacteria excretion is not successful and they often need surgical interventions.

Investigation of failure outcomes of antibacterial treatment of patients with drug resistant tuberculosis forms and analysis of the effectiveness of surgical interventions prove the high significance of surgery at this pathology [10]-[17].

\section{Work Objective}

It is to increase the effectiveness of surgical methods of treatment of patients with multidrug resistance.

\section{Materials and Methods of Investigation}

The results of treatment of 277 patients with multidrug resistance (MDR TB) were analyzed.

The first (main) group was constituted of 159 patients operated against the background of chemotherapy with standard regimens of antituberculosis drugs of the second line.

In the second (control) group there were 67 patients operated against the background of chemotherapy with standard regimens of antituberculosis drugs of the first line.

Fifty one (51) patients constituted the third (control) group treated medicamentously under conditions of the therapeutic department of the National Center for Tuberculosis Problems during the period of 2005-2008.

The number of women was 59 (37.1\%) in the first group while the number of men constituted 100 (62.9\%) relatively.

In the II and III control groups men were in 45 (67.2\%) and 33 (64.7\%) cases, while women were in 22 (32.8\%) and 18 (35.3\%) cases relatively.

The persons of the younger age were prevalent in all groups. In the first group 85 (53.4\%), in the second group 30 (44.8\%) and in the third group 23 (45.0\%) were in the age interval from 21 to 30 years.

The newly detected pulmonary tuberculosis was diagnosed in 36 (22.6\%) cases in the first group, in 16 (23.9\%) cases in the second group, and in 5 (9.8\%) cases in the third group.

Relapses of TB disease were marked in 55 (34.6\%) cases in the first group, in 28 (41.8\%) cases in the second group and 21 (41.2\%) cases in the third group.

The failure of treatment of patients with pulmonary tuberculosis occurred in 68 (42.7\%), 23 (34.3\%) and 25 (49.0\%) cases in the first, second and third groups relatively.

\section{Ethical Reasons}

Research was considered by local ethical committee at the National Center of Problems of Tuberculosis of Ministry of Health of the Republic of Kazakhstan. Each participant had been reported about the purposes, methods and potential dangers of research. Participants assured that all information collected for research, will be kept confidential, and that in any turning-out publication, it wouldn't be possible to connect data with people and families in research. Written report of the consent was received from all participants and anyone didn't reduce participation in research. Participants subscribed/struck, printed the written consent together with the witness to take part in research.

\section{Results}

In the structure of clinical forms, fibro-cavernous pulmonary tuberculosis was predominant in all groups: in the 
first group 121 (76.1\%), in the second group 31 (46.3\%) and in the third group 51 (100.0\%) cases (Table 1).

Further, percentage of tuberculoma predominated in the first group-20 (12.6\%) cases, in the second group it was presented in 5 (7.4\%) cases.

The infiltrative pulmonary TB with lung hemorrhage was marked in 12 (7.5\%) patients of the first group and in 29 (43.3\%) of the second group.

In rest of cases cavernous tuberculosis was marked: in 6 (3.8\%) and in $2(3.0 \%)$ patients of the first and second groups relatively.

At hospitalization, micobacteria tuberculosis (MBT) was identified through microscopy method in the sputum of patients of the first group in 60 (37.7\%) cases, and in 34 (50.7\%) cases in the second group. Microscopy results of the sputum on MBT were positive in $46(90.2 \%)$ patients in the third group $\left(\chi^{2}=42.514\right.$; $\mathrm{df}=2$; $\mathrm{P}<$ $0.001)$.

Cultural investigation of the sputum on MBT gave the positive results in 81 (51.0\%) persons in the first group, in $57(85.0 \%)$ patients in the second group, and in 48 (94.1\%) patients in the third group. $\left(\chi^{2}=45.504\right.$; $\mathrm{df}=2$; $\mathrm{P}$ $<0.001)$.

The test for drug resistance demonstrated the presence of multidrug resistance, i.e., MBT revealed the resistance to the isoniazid and rifampicin in all patients of three groups.

Over time treatment before operative intervention, sputum conversion confirmed by microscopy took place in 149 (93.7\%), and 57 (85\%) patients of the first and second groups.

The sputum cultural investigation showed the conversion presence in 128 (80.5\%) and $30(44.8 \%)$ cases of both groups $\left(\chi^{2}=170.723\right.$; $\left.\mathrm{df}=12 ; \mathrm{P}<0.01\right)$.

In the first group of operated patients, the negative results of culture sputum occurred reliably more frequently compared with the expected interval $(\mathrm{P}<0.01)$; in the group of operated patients against the background of inadequate chemotherapy, positive results of culture sputum occurred reliably frequently compared with expected interval $(\mathrm{P}<0.001)$.

In the third group, sputum swab conversions of the patients are observed by months (Figure 1).

\section{Table 1. Clinical tuberculosis forms in patients with MDR TB.}

\begin{tabular}{|c|c|c|c|c|c|c|c|c|}
\hline \multirow[t]{2}{*}{ Groups } & \multicolumn{2}{|c|}{$\begin{array}{l}\text { Infiltrative tuberculosis with } \\
\text { complication }\end{array}$} & \multicolumn{2}{|c|}{ Cavernous tuberculosis } & \multicolumn{2}{|c|}{ Fibrocavernous tuberculosis } & \multicolumn{2}{|c|}{ Tuberculoma } \\
\hline & abs & $\%$ & abs & $\%$ & abs & $\%$ & abs & $\%$ \\
\hline $\mathrm{I}(\mathrm{n}=159)$ & 12 & 7.5 & 6 & 3.8 & 121 & 76.1 & 20 & $12.6 \%$ \\
\hline II $(\mathrm{n}=67)$ & 29 & 43.3 & 2 & 3.0 & 31 & 46.3 & 5 & 7.4 \\
\hline III $(n=51)$ & - & - & - & - & 51 & 100.0 & - & - \\
\hline
\end{tabular}

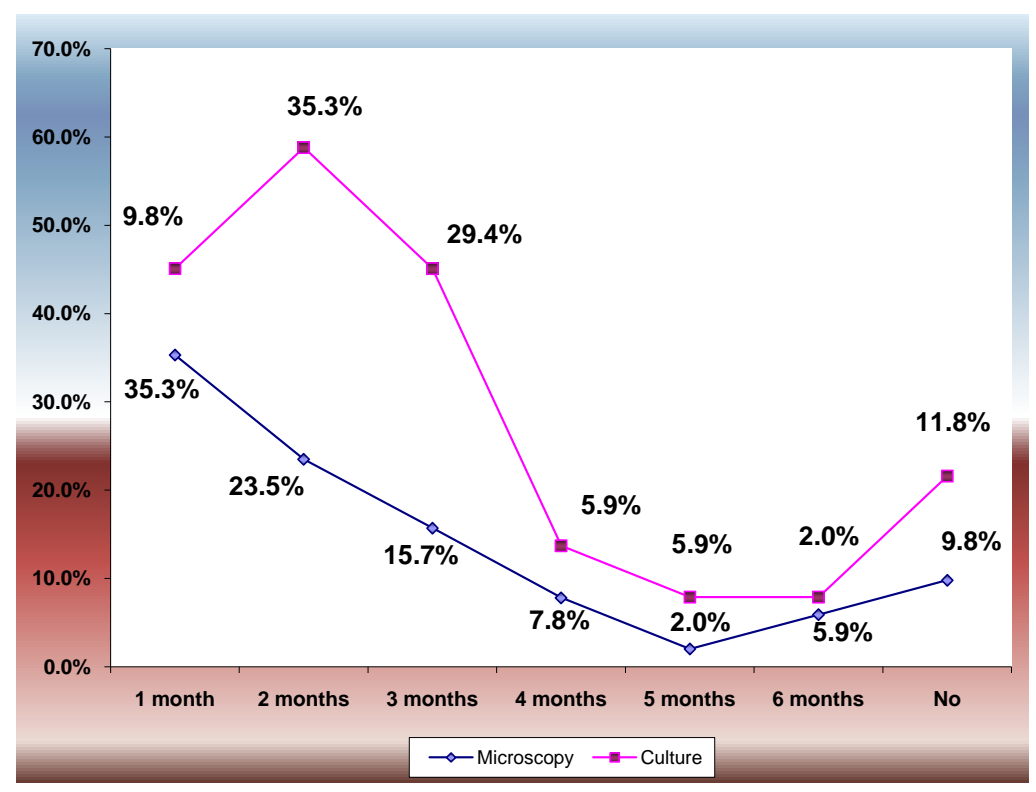

Figure 1. Terms of sputum smear conversion in patients of the third group. 
Figure 1 demonstrates that in major part of patients, 18 (35.3\%)—sputum smear conversion occurred during the first month of treatment, which was proved by smear microscopy. Cultural method of investigation showed that conversion had been obtained by second month of treatment in $18(35.3 \%)$ cases $(\mathrm{P}<0.05)$.

Further conversion occurred by $3^{\text {rd }}, 4^{\text {th }}, 5^{\text {th }}$ and $6^{\text {th }}$ months of treatment. Sputum smear conversion did not take place in 5 (9.8\%) cases microscopically and in $6(11.8 \%)$ cases culturally $(\mathrm{P}<0.05)$.

Following surgical intervention were conducted (Table 2).

The surgical treatment was implemented against the background of the intensive phase in $78.0 \%$ and in $92.5 \%$ of cases in the first and second groups correspondingly. In other cases, operations were conducted during the supporting phase of treatment.

In the earlier postoperative periods, postoperative complications in term of bronchus stump fistula were marked in 4 (2.5\%) cases in the first group versus 13 (19.4\%) cases in the second group.

Intrapleural hemorrhage and residual pleural cavity were observed in 4 (2.5\%) and 5 (3.1\%) patients of the first group.

In the second group of operated patients, postoperative complications in term of post-resection fistulae occurred reliably more frequently (H.O. $=3.5 ; \mathrm{P}<0.001$ ), while in the first group that complication was observed reliably rarely $(\mathrm{P}<0.05)$.

The postoperative complications were absent after thoracomioplasty.

The cohort analysis of examined patients was conducted (Table 3).

The successful treatment, summarizing "cure" and "treatment completed", was marked in $98.0 \%$ cases of the first group. This indicator constituted $53.7 \%$ of cases in the second group.

In the third group, percentage of patients with successful outcome of treatment constituted $74.4 \%$.

The treatment failure was registered in $0.6 \%, 28.3 \%$ and $19.6 \%$ cases in all groups correspondingly.

One patient from first group (0.6\%), 5 (7.5\%) patients from second group and 3 (5.9\%) patients from third group died.

It should be noted, that among patients of the first group, whom the thoracomioplasty was made, one $(0.6 \%)$ patient died, outcome "cured" was registered in the remained cases.

In the second group, successful outcome against the background of chemotherapy with anti-TB drugs of the first line was obtained in 22 (61.1\%) out of 36 (53.7\%) cases after collapsosurgical methods of treatment.

Table 2. Character of the operative interventions for patients of the first and second groups.

\begin{tabular}{|c|c|c|c|c|}
\hline \multirow{2}{*}{ Operations } & \multicolumn{2}{|c|}{ I группа $(\mathrm{n}=159)$} & \multicolumn{2}{|c|}{ II группа (n = 67) } \\
\hline & абс & $\%$ & абс & $\%$ \\
\hline Atypical segmental resection & 40 & 25.1 & 7 & 10.4 \\
\hline Lobectomy & 61 & 38.4 & 14 & 20.9 \\
\hline Pulmonectomy & 36 & 22.6 & 4 & 6.0 \\
\hline Combined resection & 3 & 2.0 & 1 & 1.5 \\
\hline Thoracomioplasty & 12 & 7.5 & 39 & 58.2 \\
\hline Transsternal transpericardial occlusion of the main bronchus & 5 & 3.1 & 2 & 3.0 \\
\hline Tourniquet ligation & 2 & 1.2 & - & - \\
\hline Total & 159 & 100 & 67 & 100 \\
\hline
\end{tabular}

Table 3. The treatment outcomes of patients in the groups investigated.

\begin{tabular}{|c|c|c|c|c|c|c|}
\hline \multirow[t]{2}{*}{ Outcomes } & \multicolumn{2}{|c|}{$\begin{array}{l}\text { First group } \\
n=159\end{array}$} & \multicolumn{2}{|c|}{$\begin{array}{l}\text { Second group II } \\
n=67\end{array}$} & \multicolumn{2}{|c|}{$\begin{array}{l}\text { Third group III } \\
\qquad n=51\end{array}$} \\
\hline & abs & $\%$ & abs & $\%$ & abs & $\%$ \\
\hline Cured & 148 & 93.0 & 17 & 25.4 & 27 & 52.9 \\
\hline Treatment completed & 8 & 5.0 & 19 & 28.3 & 11 & 21.5 \\
\hline Treatment failure & 1 & 0.6 & 19 & 28.3 & 10 & 19.6 \\
\hline Default & 1 & 0.6 & 2 & 3.0 & - & - \\
\hline Died & 1 & 0.6 & 5 & 7.5 & 3 & 5.9 \\
\hline Transferred to category IV & - & - & 5 & 7.5 & - & - \\
\hline
\end{tabular}


In the first group the outcome of "cured" was marked reliably more frequently in $93.1 \%(\mathrm{p}<0.001)$, outcome "treatment completed" constituted 5\% $(\mathrm{P}<0.01)$; outcome "failure" occurred reliably rarely $(\mathrm{P}<0.001)$.

In the second group outcome "failure" was marked reliably more frequently while outcome "cured" reliably rarely $(\mathrm{P}<0.001)$.

Thus, implementation of surgical methods of treatment for patients with multidrug resistance against the background of adequate chemotherapy allowed to obtain the treatment effectiveness in $98.0 \%$ cases of patients in the first group that was by 1.8 times and 1.3 times higher than the analogous results in the second and third groups.

Despite of the chemotherapy with anti-TB drugs of the first line successful outcome was registered in $61.1 \%$ cases of the second group thanks to the collapsosurgical methods.

In the follow-up period, relapses of disease occurred in 4 (2.5\%) patients of the first group, one year later.

In the second group disease relapse was observed in 13 (19.4\%) patients with outcome "treatment completed" one year later that was by 7.7 more than the number of the relapses in the first group.

In the third group relapses were marked in 7 (13.7\%) patients (by 5.4 times more than the number of relapses in the first group). Relapse occurred in 3 (5.9\%) cases year one later, in 1 (2.0\%) case two years later, in 2 (3.9\%) cases three years later, in 1 (2.0\%) four years later.

Thus, comprehensive treatment including the rational chemotherapy and surgical intervention allows to shorten the percentage of disease relapse in the follow-up period by $5.4-7.7$ times $(\mathrm{P}<0.01)$.

\section{Conclusions}

The effectiveness of surgical treatment of multidrug resistant pulmonary tuberculosis against the background of chemotherapy with anti-TB drugs of the second line constituted $98.0 \%$ that is by 1.8 times higher than among patients operated against the background of chemotherapy with anti-TB drugs of the first line $(\mathrm{P}<0.01)$.

The study of the results of surgical treatment in the follow-up period revealed that relapses were registered reliably more frequently one year later after completion of the treatment of patients with MDR TB operated against the background of the chemotherapy with anti-TB drugs of the first line (19.4\% versus $2.5 \%$ in the main group).

\section{Competing Interest}

We declare that we have no competing interest in writing this article.

\section{References}

[1] Farmer, P., Bajogna, J. and Besserra, M. (1998) Dilemme of Multidrug Resistant Tuberculosis at Present Day. In: Programme on Infectious Diseases and Social Changes, Boston, 19.

[2] Barnes, P.F. (1987) The Influence of Epidemiologic Factors on Resistance Rates in Tuberculosis. The American Review of Respiratory Disease, 136, 325-328.

[3] Khomenko, A.G., Chukanova, V.I. and Korneyev, A.A. (1996) In Russian: Effectiveness of Chemotherapy of Pulmonary Tuberculosis with Drug-Resistant Mycobacteria (Efficiency of Chemotherapy of Tuberculosis of Lungs with Multi Drug Mykobakteria. Journal of the Problems of Tuberculosis and of Lungs Diseases, 6, 42- 44.

[4] Dorozhkova, I.R. (1998) In Russian: Problems of Drug Resistance of Mycobacteria under Conditions of Up-Today Epidemiological Situation (The problems of Medicinal Stability of a Mikobakteriya in the Conditions of a Modern Epidemiological Situation. International Conference on Control of Tuberculosis and Y Congress of Phthisiaters of Kazakhstan, Almaty, 126.

[5] Tkachenko, S.O. and Obodzinskij, V.N. (2003) In Russian: Causes of Non-Effectiveness of Treatment of the Patients with Newly Detected Pulmonary Tuberculosis (The Principles Not Efficiency of Treatment of Patients with for the First Time Revealed Tuberculosis. Tuberculosis Today. Materials of the Russian Congress YII of Phthisiaters, Moskow, 249.

[6] Vernon, A. (2001) How Long We Treat TB. The International Journal of Tuberculosis and Lung Disease, 5, 7.

[7] Dilmagambetov, D.S. (2002) In Russian: Clinics, Diagnostics and Treatment of Newly Detected Tuberculosis of Breathing Organs at Presence of Primary Drug Resistance of Tuberculosis Mycobacteria (Clinic, Diagnostics and Treatment for the First Time the Revealed Patients with Tuberculosis of Respiratory Organs with Primary Drugs Resistance of Mykobakteria of Tuberculosis: Abstract of PhD.: 23.04.02. 24). Almaty, 24. 
[8] Ismailov, S.S. and Dautova, K.M. (2001) In Russian: Effectiveness of the Anti-TB Drugs of the Third Line for Treatment of Polyresistant Chronic Tuberculosis (Efficiency of Reserve Preparations in Treatment of Polyresistant Chronic of Pulmonary Tuberculosis. Up-Today Principles of Treatment and Monitoring of Multidrug Resistant Tuberculosis (Modern Principles of Treatment and Monitoring of Multiresistant Tuberculosis). Almaty Coвр, Almaty, 86-91.

[9] Khomenko, A.G., Mishin, V.Y. and Chukanova, V.I., et al. (1999) In Russian: Diagnostics, Clinics and Tactics of Treatment of Acute Progressing Tuberculosis Forms of Pulmonary Tuberculosis in Up-Today Conditions (Diagnostics, Clinic and Treatment Tactics the Extensive of Forms of Tuberculosis in Modern Epidemiological Conditions. The International Journal of Tuberculosis and Lung Disease, 22-26.

[10] Dzhunusbekov, A.D. (1964) In Russian: Resections of Lungs in Patients with Drug Resistance of Tuberculosis Mycobacteria (The Resection of Lungs at Patients with Medicinal Stability of Mykobakteria of Tuberculosis: Abstract of PhD.: 21.10.64). Moscow, 19.

[11] Perelman, M.I. (1997) Surgery at Tuberculosis (The Surgery of Tuberculosis). Materials of the International Conference, Moscow, 14-15.

[12] Repin, Y.M. (1984) Surgery of the Complicated Forms of Tuberculosis of Lungs. Medicine, St. Petersburg, 87-89.

[13] Frolov, G.A., Popkova, N.L. and Kalashnikov, A.V. (2002) Outcomes of Surgical Treatment of Patients with Pulmonary Tuberculosis with Drug Resistance (The Results of Surgical Treatment of Patients with Tuberculosis of Lungs with Drugs Resistant). The Problems of Tuberculosis and of Lungs Diseases, 15-18.

[14] Jzeman, M.D. (1993) Treatment of Multidrug Resistant Tuberculosis. New England Journal of Medicine, 329, 781791.

[15] Rink, H. (1965) Die heutige Bedeutung des Kollapsprinzips in des chirurgischeu Behandlung des Lungentuberkulose. Thoraxchirgi, 13, 177-181.

[16] Streltsov, V.P. and Chefranov, V.S. (1979) Ways of Enhancement of Effectiveness of Surgical Treatment for Patients with Advanced Forms of Pulmonary Tuberculosis (The Ways of Increase of Efficiency of Surgical Treatment of Patients with Widespread Forms of Pulmonary Tuberculosis). In: Up-Today Methods of Detection and Elimination of Tuberculosis Infection Sources (Modern Methods of Detection and Elimination of Sources of Infection of Tuberculosis), Moscow, 131-133.

[17] Aliyev, A.A. (1987) Outcomes of Surgical Treatment in Patients with Advanced (Heavy) Forms of Pulmonary Tuberculosis over Last Five Years. In: Collection Book: Materials of IY Caucasian Congress of Phthisiaters, Baku, 125-126. 